\title{
Systematic Review \\ The Role of Neural Network for the Detection of Parkinson's Disease: A Scoping Review
}

\author{
Mahmood Saleh Alzubaidi ${ }^{1, *(\mathbb{D}, \text { Uzair Shah }}{ }^{1}{ }^{1}$, Haider Dhia Zubaydi ${ }^{2}$, Khalid Dolaat $^{1}$, Alaa A. Abd-Alrazaq ${ }^{1}$, \\ Arfan Ahmed ${ }^{1}$ (ID and Mowafa Househ 1,*(D) \\ 1 College of Science and Engineering, Hamad Bin Khalifa University, Doha 53, Qatar; \\ uzsh31989@hbku.edu.qa (U.S.); khdo31645@hbku.edu.qa (K.D.); aabdalrazaq@hbku.edu.qa (A.A.A.-A.); \\ arahmed@hbku.edu.qa (A.A.) \\ 2 National Advanced IPv6 Centre, Universiti Sains Malaysia, Gelugor 11800, Malaysia; haidardhia@yahoo.com \\ * Correspondence: maal28902@hbku.edu.qa (M.S.A.); mhouseh@hbku.edu.qa (M.H.)
}

check for

updates

Citation: Alzubaidi, M.S.; Shah, U.; Dhia Zubaydi, H.; Dolaat, K.;

Abd-Alrazaq, A.A.; Ahmed, A.;

Househ, M. The Role of Neural

Network for the Detection of

Parkinson's Disease: A Scoping

Review. Healthcare 2021, 9, 740 .

https://doi.org/10.3390/

healthcare 9060740

Academic Editor:

Mahmudur Rahman

Received: 25 April 2021

Accepted: 26 May 2021

Published: 16 June 2021

Publisher's Note: MDPI stays neutral with regard to jurisdictional claims in published maps and institutional affiliations.

Copyright: (c) 2021 by the authors. Licensee MDPI, Basel, Switzerland. This article is an open access article distributed under the terms and conditions of the Creative Commons Attribution (CC BY) license (https:/ / creativecommons.org/licenses/by/ $4.0 /)$.
Abstract: Background: Parkinson's Disease (PD) is a chronic neurodegenerative disorder that has been ranked second after Alzheimer's disease worldwide. Early diagnosis of PD is crucial to combat against PD to allow patients to deal with it properly. However, there is no medical test(s) available to diagnose PD conclusively. Therefore, computer-aided diagnosis (CAD) systems offered a better solution to make the necessary data-driven decisions and assist the physician. Numerous studies were conducted to propose CAD to diagnose PD in the early stages. No comprehensive reviews have been conducted to summarize the role of AI tools to combat PD. Objective: The study aimed to explore and summarize the applications of neural networks to diagnose PD. Methods: PRISMA Extension for Scoping Reviews (PRISMA-ScR) was followed to conduct this scoping review. To identify the relevant studies, both medical databases (e.g., PubMed) and technical databases (IEEE) were searched. Three reviewers carried out the study selection and extracted the data from the included studies independently. Then, the narrative approach was adopted to synthesis the extracted data. Results: Out of 1061 studies, 91 studies satisfied the eligibility criteria in this review. About half of the included studies have implemented artificial neural networks to diagnose PD. Numerous studies included focused on the freezing of gait (FoG). Biomedical voice and signal datasets were the most commonly used data types to develop and validate these models. However, MRI- and CT-scan images were also utilized in the included studies. Conclusion: Neural networks play an integral and substantial role in combating PD. Many possible applications of neural networks were identified in this review, however, most of them are limited up to research purposes.

Keywords: Parkinson's disease; neural network; deep learning; classification

\section{Introduction}

\subsection{Background}

The human brain is the primary controller part of the human body. Any minor damage to any of its parts will severely affect other organs-one of its adverse effects is Parkinson's disease (PD) [1]. "PD is a chronic and progressive neurodegenerative disease" [2], and it occurs mainly in people over 50 years old [3]. Its symptoms start slowly and increase over time. PD symptoms are characterized such as motor and nonmotor [4]. Motor symptoms include movement disorders, shaking, walking issues [5], stiffness, and postural instability [6], while nonmotor symptoms including cognitive dysfunction, mood disorder [7], depression, and anxiety [8].

Parkinson's is the second worse neurodegenerative disease worldwide after Alzheimer's disease. In 2019, its incident rate ranged from 40.37 to 53.89 per 100,000 population per year in the US alone [9]. Diagnosis of PD in an early stage is an important issue to mitigate its complications. However, no medical test is available to diagnose it in the early stages conclusively. In a traditional clinical setup, the physician 
will ask the patient to perform some mental and physical tasks (e.g., moving and walking around) [10] or take the magnetic resonance imaging (MRI) and/or Positron emission tomography-computed tomography (PET/CT) scan of the brain. However, it is challenging to differentiate PD from other neurological disorders, and it depends on the radiologist's experience to distinguish and identify it precisely. Therefore, a computer-aided diagnosis (CAD) system helps the radiologist interpret MRI scans. In 2003, the authors of [7] made a CAD system to monitor body acceleration to detect the freezing of gait in PD patients.

Several studies were conducted to implement machine learning approaches to detect $\mathrm{PD}$ and differentiate it from other common neurological diseases. Feature engineering is the difficult part of deploying such systems, and it is expensive to identify the relevant features in the data. When automatic feature extraction methods and techniques $(\mathrm{CNN}$, $\mathrm{RNN}$ ) were proposed, most researchers used deep learning and neural network to detect PD due to automatic feature extraction, learning more complex patterns, and high accuracy. Therefore, this scoping review aims to explore and summarize the applications of deep learning and neural network in PD diagnosis.

\subsection{Research Problem and Objectives}

The scope of this paper is limited to the detection of Parkinson's disease (PD) in the early stage using neural networks. The patient dataset such as electronic health record (EHR) and medical image can be analyzed using neural network (NN) features; in particular, patient's data can undergo many processes; analysis, segmentation, augmentation, scaling, normalization, sampling, aggregation, and sifting, in order to obtain accurate prediction that assists healthcare ecosystem and stakeholders in the healthcare domain. Many studies have been recently conducted to address and propose a solution to mitigate and prevent neurodegenerative disorders such as PD. However, most of these studies and research are dispersed. Therefore, summarizing NN technologies' involvement in resolving challenges related to PD is needed; an appropriate summarization allows new researchers to understand the current role of neural networks against PD. It will open new opportunities for researchers to have the necessary base that allows them to build on instead of starting from ground zero.

Many studies have been carried out to cover AI techniques that have been used to mitigate and prevent PD [11-14]. These approaches are conducted in reviews or surveys that generally focus on artificial intelligence (AI) applications such as patient diagnosis, epidemiological monitoring, and drug and vaccine discovery [15]. Nevertheless, a massive number of research papers are constantly being published, which has overwhelmed electronic databases. Therefore, it is necessary to carry out an updated review that focuses on the uses of neural networks in PD prevention.

This review aims to identify and illustrate neural network technology's role in detecting PD early, based on the following aspects: (1) identifying the role of neural networks in PD detection, (2) highlighting the recent algorithms applied on PD datasets, (3) observing dataset types, (4) categorizing the type of PD based on symptoms, (5) investigating the best results achieved by the research community, and (6) providing a recommendation for researchers and healthcare individuals. The outcome can be used in the healthcare sector as guidance for developers who consider neural network's utilization to improve the public health capability as a response to PD.

\section{Methodology}

We carried out a scoping review to explore the evidence on neural network's application in diagnosing Parkinson's disease in a structured manner. In this section, we listed the details of the adopted methodology to conduct this review. For this purpose, PRISMA Extension for Scoping Reviews (PRISMA-ScR) [16] was used for this scoping review. 


\subsection{Search Strategy}

\subsubsection{Search Sources}

We selected five bibliographic databases (PubMed, IEEE, ACM, ScienceDirect, and Google Scholar) to retrieve the research studies relevant to the topic. We scanned only 100 articles from Google Scholar; these articles were chosen after scanning based on their relevance to fit this paper. The backward and forward reference checking lists were not performed due to the sufficient number of included studies. The search process was performed from 24 February to 1 March 2021.

\subsubsection{Search Terms}

In the present review, we considered two different search terms based on population and intervention. Given the population of "Parkinson's disease" and intervention of "deep learning", the search strategy was conducted as follows: (("Parkinson's disease" OR "Parkinson" (" artificial intelligence* "OR " machine learning" OR " neural network" ${ }^{*}$ " " deep learning" OR "natural language processing" OR "neural network" OR "unsupervised learning" OR "ensemble learning" OR "reinforcement learning")) total retrieved studies in (Appendix A).

\subsection{Study Eligibility Criteria}

This study aims to summarize and review the application/use of deep learning, particularly in diagnosing Parkinson's disease. Therefore, only the following studies were eligible to satisfy the below criteria: a deep learning approach or technique introduced or developed that primarily focused on diagnosing Parkinson's disease. Further, some constraints on the types of publication and the language of the studies were made. Only studies published in English between 2018 and 2021 are selected, and only peer-reviewed articles, conference proceedings, reports, theses, dissertations were admitted. Reviews, conference abstracts, commentaries, proposals, editorials were excluded. The details of exclusion and inclusion for study selection are listed in Table 1.

Table 1. Inclusion and exclusion criteria.

\begin{tabular}{lll}
\hline Criteria & & \multicolumn{1}{c}{ Specified Criteria } \\
\hline & - & \multicolumn{1}{c}{$\begin{array}{l}\text { Studies that aim to diagnose Parkinson's using deep learning } \\
\text { technique or approach }\end{array}$} \\
Inclusion & - & Studies that published from 2018 onwards \\
& Empirical studies only \\
& - Only written in English \\
\hline Exclusion & - & Abstract \\
& - & Neview including an overview, scoping review, etc. \\
& - Nonglish studies \\
&
\end{tabular}

\subsection{Study Selection}

The study selection process was conducted in two stages (screening title and abstracts of retrieved studies and screening full text of the studies selected in the first stage). In the first stage, the first reviewer, MA, independently screened all the retrieved studies' titles and abstracts; due to time constraints, the second reviewer, US, and the third reviewer, KD, reviewed the first half and second half of the complete set of articles, respectively. The Rayyan software, a web-based systematic review tool, was employed for screening title and abstract [17]. In the second stage, the first reviewer, MA, performed the first stage's full-text screening of the identified studies. Any disagreement between reviewers was resolved through consensus and discussion. 


\subsection{Data Extraction and Data Synthesis}

To extract the study-specific information and data, an extraction form was created and tested by eight included studies (Appendix B). MA and US undertook the data extraction, and the data were extracted to the excel sheet to summarize the following: general characteristic of included studies (e.g., country, types, and year of publication), aim/purpose of the study, type of Parkinson's disease, branch/type neural network, type of validation, performance metrics, the dataset used to train and test the model, number of Parkinson's and healthy samples, type of dataset, size of the dataset, data collection device or sensor, and dataset source. We used the narrative approach to synthesis the extracted data.

\section{Results}

\subsection{Search Results}

In total, 1061 studies were retrieved by searching through 5 recognized E-Databases. Then, 190 (17.90\%) were removed due to duplication, while 871 (82.09\%) went through title and abstract screening; in this screening, we excluded $598(56.36 \%)$ studies due to various reasons, as shown in Figure 1. The remaining 273 (25.73\%) studies went through the full-text screening, and $181(17.05 \%)$ studies were excluded, as detailed in Figure 1. In total, $91(8.67 \%)$ studies were included in this review.

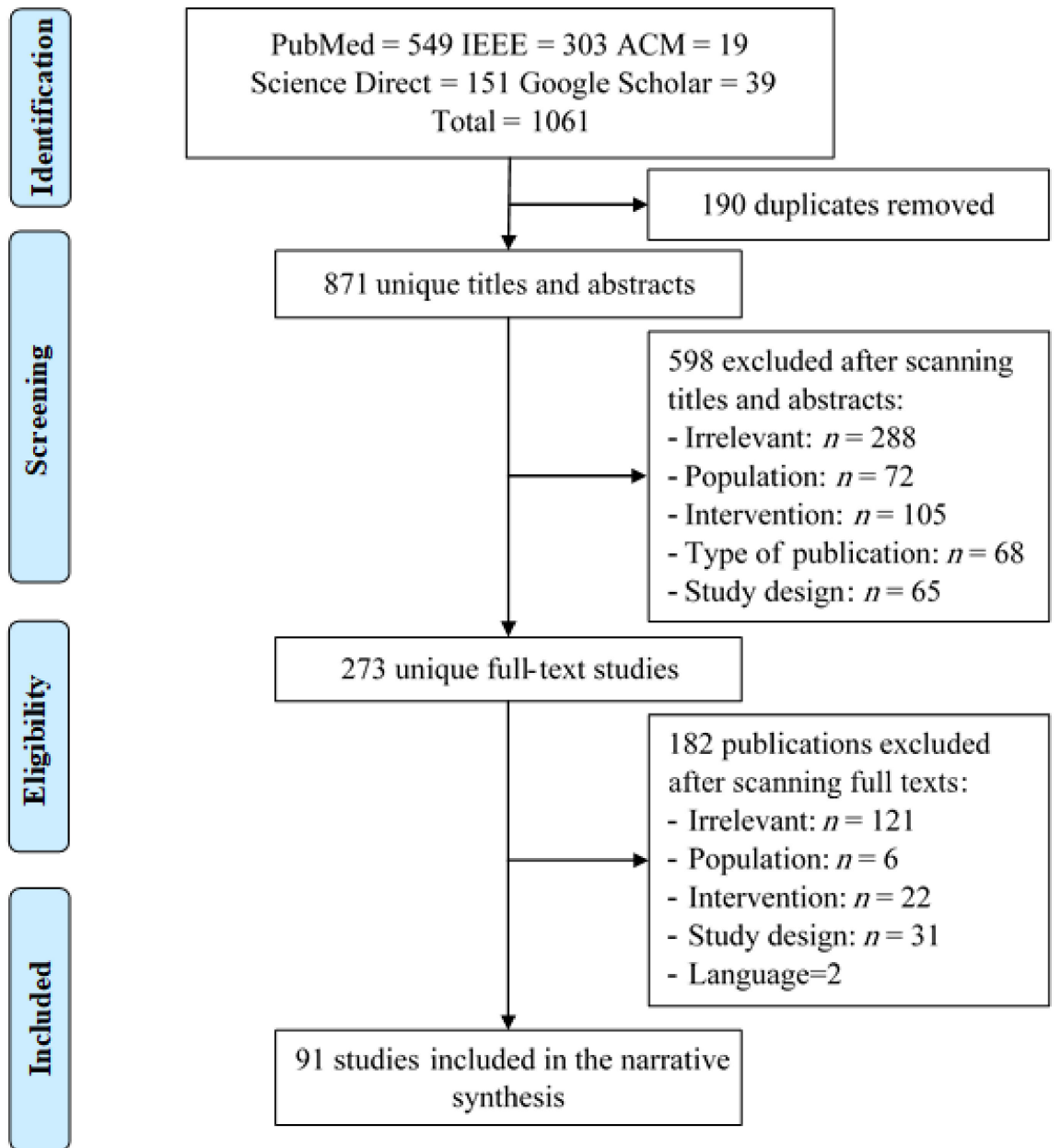

Figure 1. PRISMA chart.

\subsection{General Description of the Included Studies}

As shown in Table 2, the included citations were published in more than 30 different countries, as shown in Figure 2, about 13 studies from the US (14.13\%), followed by 9 studies from China and India (9.78\%) (Figure 3). This shows that numerous papers were 
published in the last 3 years; for instance, 30 papers (32.60\%) were published in 2019 and 2020. More than half $(56.2 \%)$ of the included studies were conference papers. However, most conference papers $(n=18)$ were published in 2018, and 2020, respectively, and only $(n=16)$ conferences article were reported in 2019. In addition, $(n=39)$ journal articles were published in last few years: $(n=10)$ in $2018 ;(n=14)$ in 2019; $(n=12)$ in 2020; and $(n=3)$ in 2021.

Table 2. General characteristics of the included studies $(n=91)$.

\begin{tabular}{|c|c|c|}
\hline Characteristics & Studies, $n(\%)$ & Ref. \\
\hline \multirow{4}{*}{ Year of publication } & 2021: $4(4.34)$ & {$[6,18-20]$} \\
\hline & 2020: $30(32.60)$ & {$[21-51]$} \\
\hline & 2019: $30(32.60)$ & {$[4,52-85]$} \\
\hline & 2018: 28 (30.43) & {$[3,86-105]$} \\
\hline \multirow{32}{*}{ Country } & US: 13 (14.13) & {$[18,27,29,57,61,65,74,82,87,88,92,95,104]$} \\
\hline & China: 9 (9.78) & {$[33,40,52,53,66,67,85,89,90]$} \\
\hline & India: $9(9.78)$ & {$[3,31,37,50,51,55,60,63,105]$} \\
\hline & Canada: 6 (6.52) & {$[35,38,45,46,83,93]$} \\
\hline & UK: 4 (5.43) & {$[48,58,62,103]$} \\
\hline & Korea: 4 (4.34) & {$[30,41,56,98]$} \\
\hline & Turkey: 4 (4.34) & {$[4,36,77,101]$} \\
\hline & Brazil: 3 (3.26) & {$[75,97,102]$} \\
\hline & Australia: 3 (3.26) & {$[20,42,100]$} \\
\hline & Italy: $3(3.26)$ & {$[21,49,96]$} \\
\hline & Spain: 3 (3.26) & {$[76,91,94]$} \\
\hline & Greece: $2(2.17)$ & {$[54,99]$} \\
\hline & Bangladesh: 2 (2.17) & {$[44,59]$} \\
\hline & Japan: $2(2.17)$ & {$[6,72]$} \\
\hline & Lebanon: 2 (2.17) & {$[68,69]$} \\
\hline & Malaysia: 2 (2.17) & {$[39,84]$} \\
\hline & Germany: 2 (2.17) & {$[71,79]$} \\
\hline & Morocco: 2 (2.17) & {$[23,25]$} \\
\hline & Saudi Arabia: 2 (2.17) & {$[28,80]$} \\
\hline & Singapore: 2 (2.17) & {$[32,81]$} \\
\hline & Belgium: $1(1.08)$ & [43] \\
\hline & Colombia: 1 (1.08) & [70] \\
\hline & France: 1 (1.08) & [47] \\
\hline & Lithuania: 1 (1.08) & [22] \\
\hline & Netherlands: 1 (1.08) & [78] \\
\hline & Pakistan: 1 (1.08) & [86] \\
\hline & Palestine: 1 (1.08) & [73] \\
\hline & Portugal: 1 (1.08) & [64] \\
\hline & Russia: 1(1.08) & [26] \\
\hline & Slovakia: 1 (1.08) & [19] \\
\hline & Romania: 1 (1.08) & [24] \\
\hline & Egypt: 1 (1.08) & [34] \\
\hline \multirow{2}{*}{ Type of publication } & Conference: 52 (56.52) & $\begin{array}{l}{[3,18,21-27,29-31,36,44-51,53-61,63-66,68-} \\
71,74,77,79,81-89,92,95,96,99-105]\end{array}$ \\
\hline & Journal article: 39(42.39) & $\begin{array}{l}{[4,6,19,20,28,32-35,37-43,52,62,67,72,73,75} \\
76,78,80,90,91,93,94,97,98]\end{array}$ \\
\hline
\end{tabular}




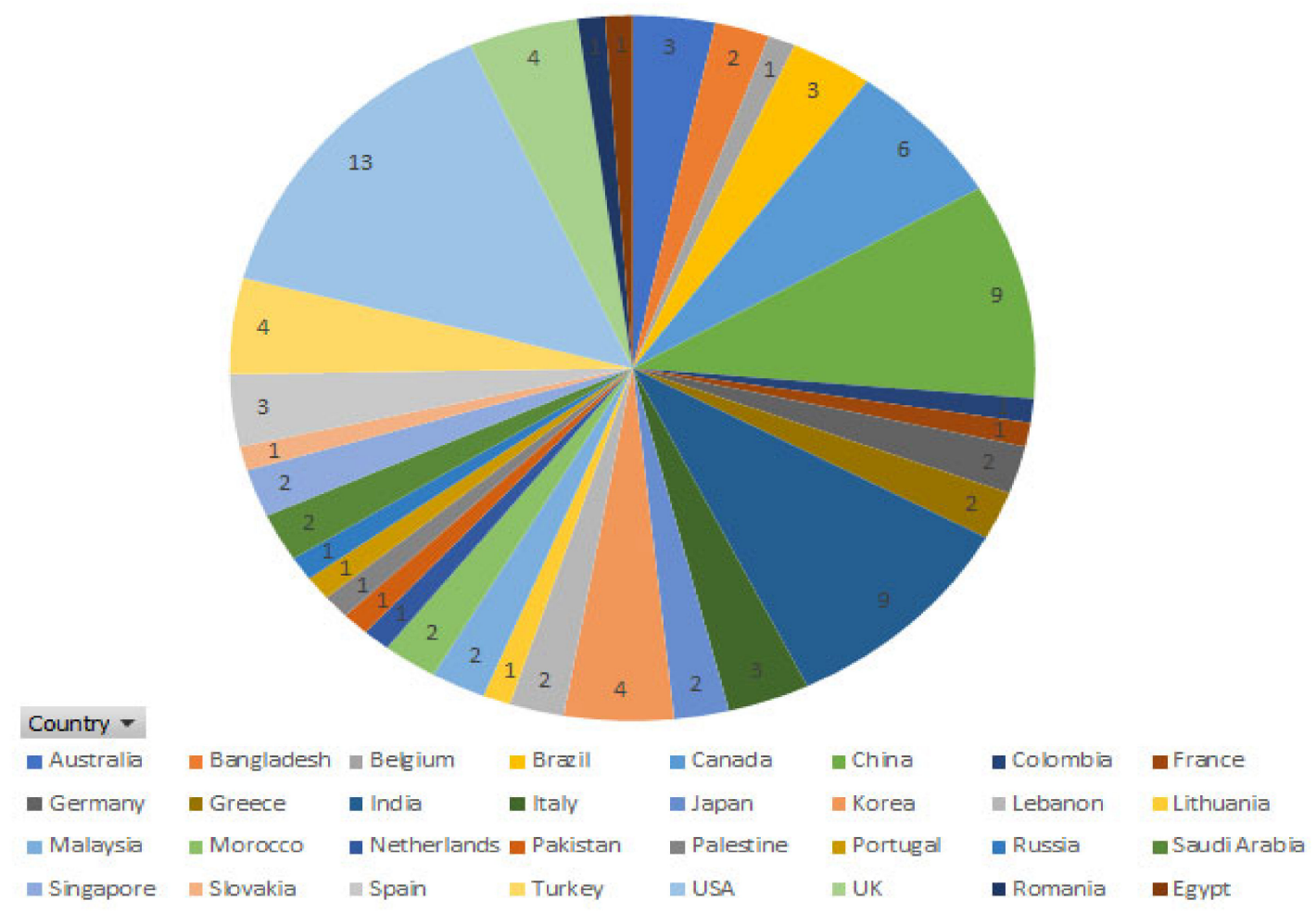

Figure 2. Number of publications for each country.

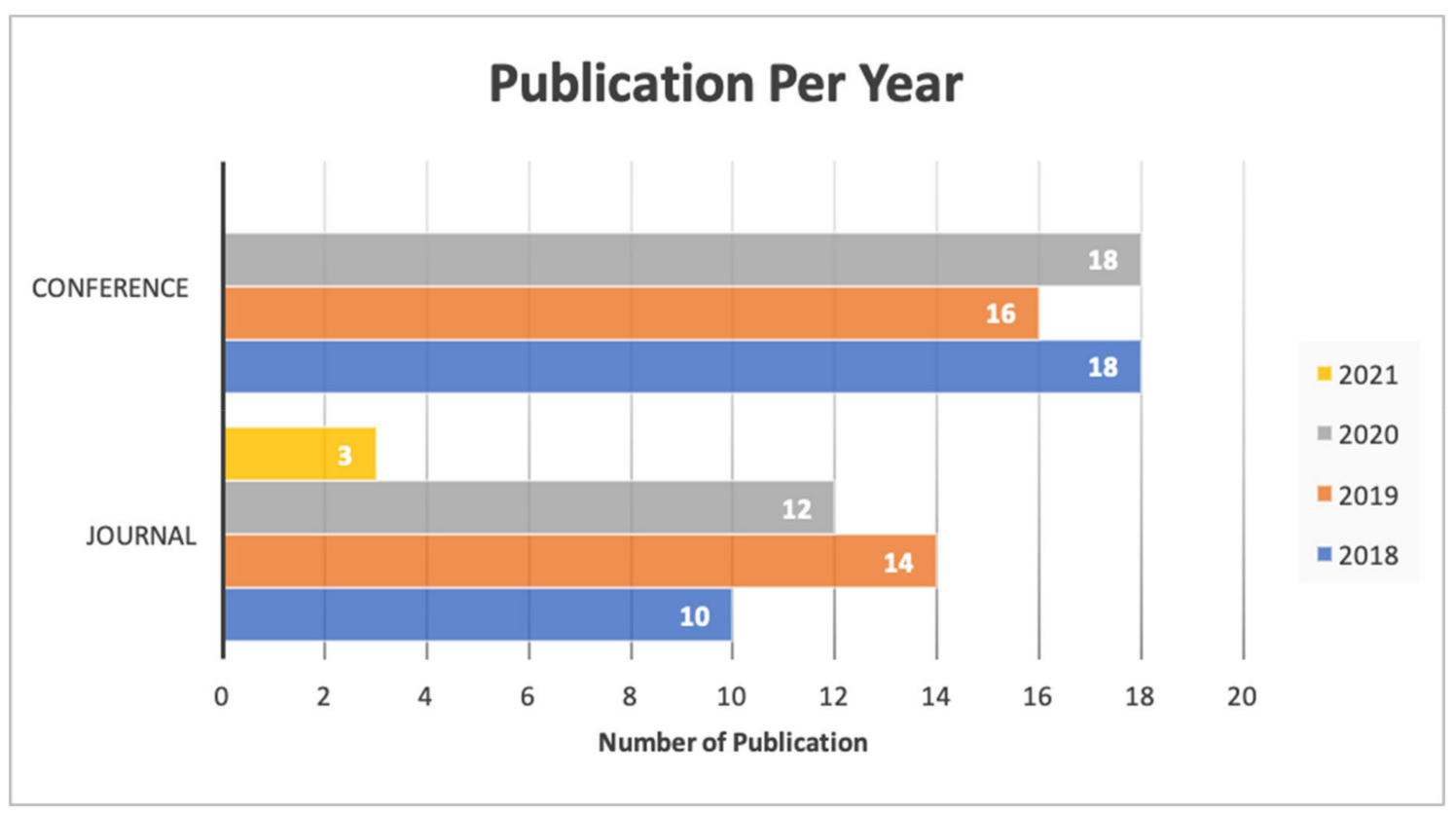

Figure 3. Type of publication and year.

\subsection{Description of Detection Techniques}

The study's primary aim is to investigate the role of neural networks in the diagnosis of PD. We classified neural networks into five well-known algorithms used in the included studies: CNNs, RNNs, FNNs, ANNs, and other NNs. Around half of the included studies used convolution neural networks $(n=37)$; afterward, other neural networks $(n=31)$ were implemented in the included studies, followed by artificial neural networks (ANNs) $(n=10)$, recurrent neural networks (RNNs) $(n=9)$, and fuzzy neural networks (FNNs), as shown in Table 3. In the end, the most imitated neural network architec- 
ture in the included studies was LSTM $(n=11)[6,34,36,38,40,65,70,74,77,80,83]$, VGG $(n=3)[18,27,58]$, and DNN $(n=6)[34,35,60,91,92,103]$. Recently, with the developments of new techniques such as convolutional neural network [101] and transfer learning [63], deep learning gained significant advances in the computer vision tasks, e.g., ImageNet [77]. Therefore, most of the studies used different imaging data to diagnose PD, such as MRI $(n=12)[41,47,54,56,58,66,72,78,82,86,90,95]$ and handwritten images $(n=9) \quad[3,19,25,30,69$, $75,101,102]$, as well as PET and CT imaging $(n=6)[28,59,67,71,88,90]$ and DaTscan imaging $(n=4)[54,76,99,103]$. However, $\mathrm{CNN}$ and transfer learning techniques were not limited to imaging data; they also learn complex features from voices and signal data [29]. Numerous studies used the biomedical voice $(n=21)[4,6,22,23,29,33,44,48,50,52,53,55,60,61,73,74$, $84,93,100,104,105]$ and biometric signal $(n=14)[26,31,34,36,45,46,57,62,64,65,68,89,96,98]$; a few of the included studies used EEG and EMG signals $(n=5)[32,39,51,83,85]$.

As shown in Figure 4, some studies target specific symptoms of PD, such as freezing of gait, vocal impairment, and tremor disorder. A more limited number of included studies proposed a deep learning approach to detect tremor disorder $(n=5)$ and vocal impairment $(n=13)$. However, various studies used the deep learning technique to diagnosis PD $(n=50)$, in general, and freezing of gait $(\mathrm{FoG})(n=23)$, in particular.

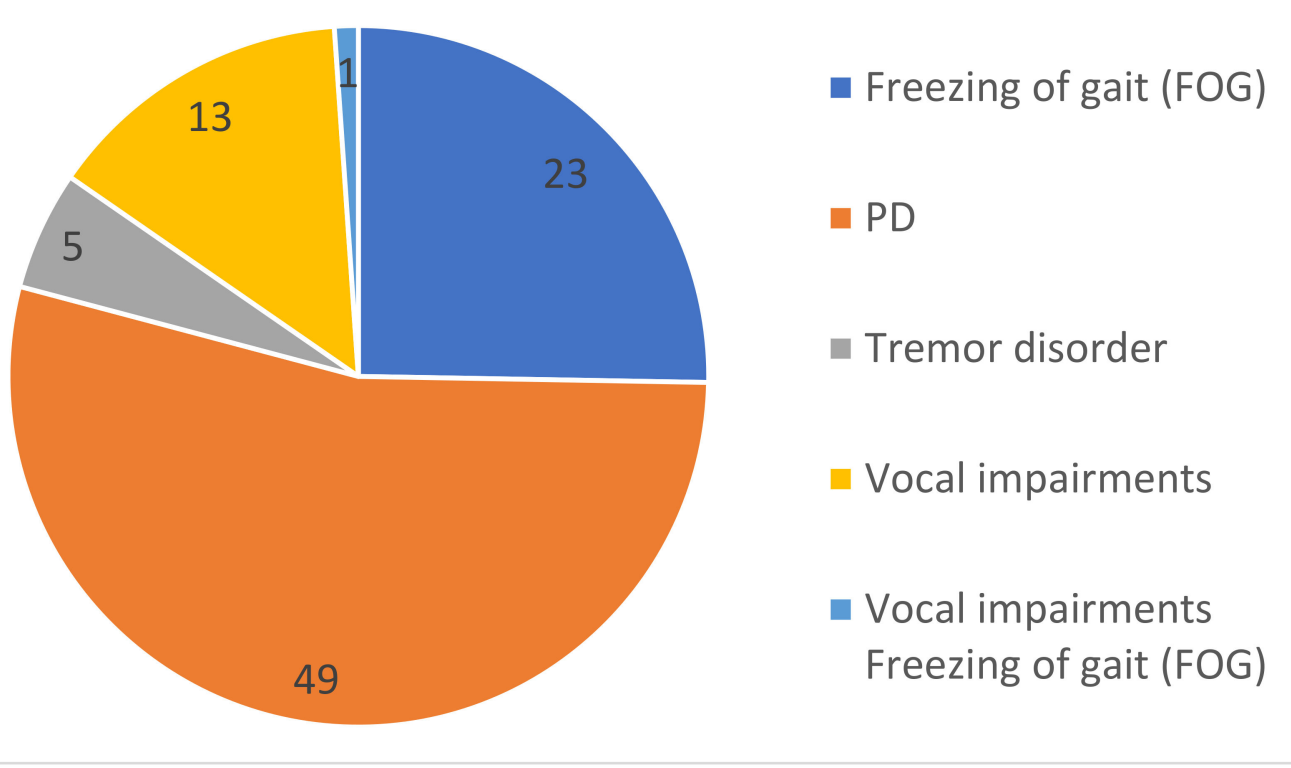

Figure 4. Different symptoms of Parkinson's disease in the included studies.

As reported in Table 3, the neural network is divided into five main branches (CNN, RNN, ANN, FNN, NN); all types of subclassification techniques are listed as backbone model; moreover, we noticed that LSTM was heavily used in a different study $(n=11)$, followed by none deep learning classifier SVM $(n=8)$; however, we have reported SVM in this review because many studies used neural networks to perform data extraction, but the classification was handled by the machine learning classifier such as SVM; hence, DNN was used and reported in $(n=6)$, and a predefined model such as VGG was used in $(n=3)$; other types of algorithms that were used rarely depended on each of the studies' design or achieved a remarkable result. 
Table 3. Description of PD detection techniques $(n=91)$.

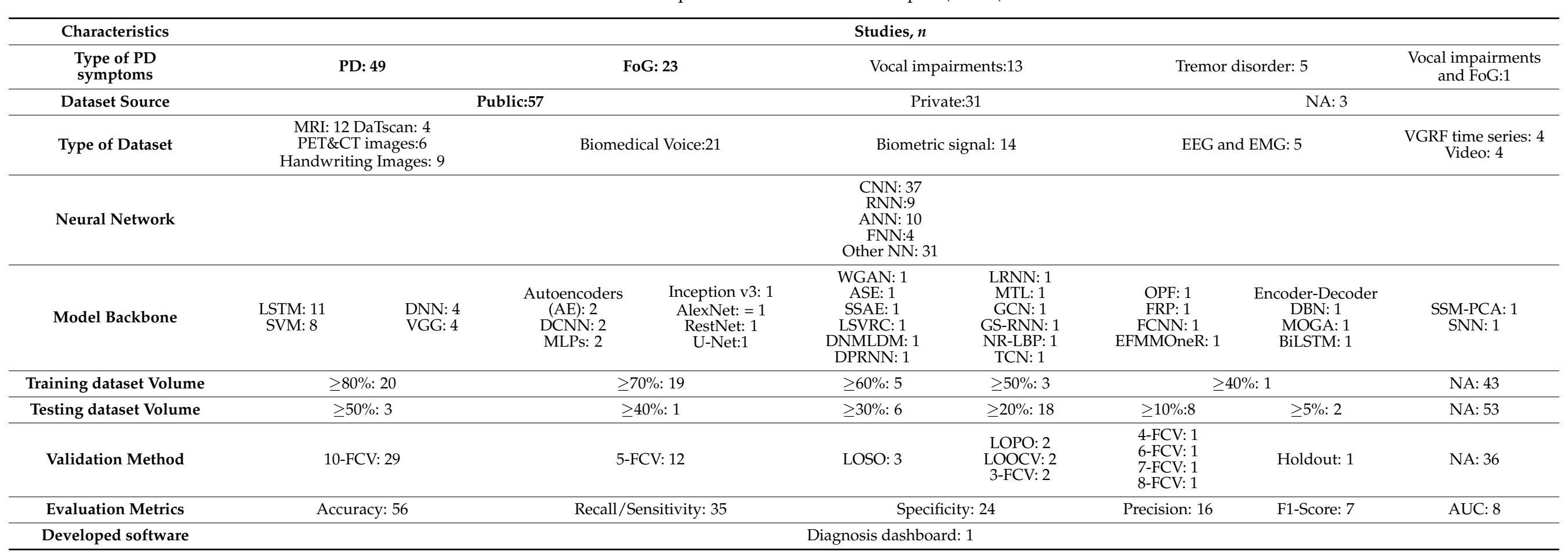


In most of the studies, the dataset was divided into three parts training, testing, and validation due to the limited number of studies that divided the datasets only into the training set and validation set, as presented in Table 3. We reported only the training and testing datasets. Furthermore, most of the experiments $(n=21)$ used $\geq 80 \%)$ volume of the training dataset, and $(n=9)$ used $(\geq 70 \%)$. However, only few experiments provided less volume of the training dataset, as seen in $(n=5)$ used $(\geq 60 \%)$ and $(n=3),(n=1)$ used $(\geq 50 \%),(\geq 40 \%)$, respectively. However, $(n=43)$ of the studies did not mention the volume of the training dataset. In addition, the volume of the testing dataset is not clarified in most of the studies; we noticed that $(n=53)$ did not specify the volume of the testing dataset that was used during the experiment; however, the volume of $(\geq 20 \%)$ was mostly used in $(n=18)$, followed by $(\geq 10 \%)$ that were mentioned in $(n=9)$, and the volume of $(\geq 30 \%)$ was observed in $(n=6)$. The testing dataset is usually used in low volume, compared to the training dataset; however, we noticed that half of the dataset $(\geq 50 \%)$ was used only in $(n=3)$. In addition, low volumes of testing dataset, i.e., $(\geq 5 \%)$ and $(\geq 40 \%)$, are reported in $(n=2)$ and $(n=1)$, respectively.

The validation method is highly considered in this review; we have reported all the studies' validation mechanisms. The most common K-fold cross validation (K-FCV) methods used are the tenfold cross-validation, which was used in $(n=30)$, followed by fivefold cross-validation in $(n=12)$, whereas fewer K-FCV methods were reported as threefold cross-validation, fourfold cross-validation, sixfold cross-validation, sevenfold cross-validation, and eightfold cross-validation in $(n=2),(n=1),(n=1),(n=1)$, and $(n=1)$, respectively. Furthermore, other validation methods such as LOSO, LOPO, LOOCV, and holdout were rarely used, and are reported in $(n=3),(n=2),(n=2)$, and $(n=1)$, respectively. However, $(n=36)$ did not mention any type of validation method within their experiments.

Various evaluation metrics used to check each model's performance and accuracy are the most commonly used metrics to calculate the model's efficiency in predicting the result based on the testing dataset. In $(n=57)$, the accuracy of the models was reported. On the other hand, along with the accuracy, other evaluation methods were used, such as recall/sensitivity that was reported in $(n=36)$, followed by specificity in $(n=24)$ and precision $(n=17)$; however, few studies $(n=8)$ used area under the curve (AUC) as an evaluation metric.

During summarization of all $(n=91)$ results, unfortunately, we did not come across any empirical validation/real-life implementation in any hospital. Moreover, from the $(n=91)$ studies, we only found one study that developed diagnosis software that identified any neurological disorders such as PD and that can be employed in the medical center [51].

\subsection{Dataset Description}

\subsubsection{Public Dataset}

As discussed, an earlier total number of the public dataset $(n=57)$, Table 4 , summarized the most used $(n=36)$ public available dataset sources and repositories $(n=36)$, e.g., Parkinson Progression Markers Initiative database (PPMI), UCI database repo, and PhysioNet; these were the most used datasets to develop and validate the AI models. Other public dataset sources used by the included studies were as follows: Kaggle, HandPD, DaphNet, the NTUA Parkinson Dataset, Neurovoz corpus, PC-GITA database, etc.

Table 4 only provides a sample of the public datasets used within the included studies. As seen, the number of males in the PD sample is higher than the number of females, and the number of males in healthy control is higher than the number of females in most cases. Furthermore, different types of hardware devices were used to collect the dataset; we have noticed that most of the data are in the form of images collected with different devices, starting from hospital imaging device including MRI, CT, DaTscan and ending with smartphone images that were used to capture handwriting or drawing of the PD samples $(n=28)$ and $(n=4)$ for recording video. 
Table 4. Public dataset descriptions.

\begin{tabular}{|c|c|c|c|c|c|c|c|}
\hline \multirow{2}{*}{ Dataset } & \multirow{2}{*}{ Source/Host } & \multirow{2}{*}{ Used Device/Sensor } & \multicolumn{2}{|c|}{ Number of PD Patient } & \multicolumn{2}{|c|}{$\begin{array}{c}\text { Number of } \\
\text { Healthy Control }\end{array}$} & \multirow{2}{*}{ Ref. } \\
\hline & & & Male & Female & Male & Female & \\
\hline \multirow{10}{*}{ Public } & PhysioNet $(n=4)$ & $\begin{array}{c}16 \text { sensors } \\
\text { s under each foot } 8 \text { per foot }\end{array}$ & 59 & 34 & 40 & 32 & {$[21,49,55,81]$} \\
\hline & $\begin{array}{l}\text { The University of California, } \\
\text { Irvine Machine Learning repository } \\
\text { UCI }(n=10)\end{array}$ & NA & 84 & 40 & 23 & 41 & $\begin{array}{c}{[3,4,23,33,44,53,55,60} \\
84,105]\end{array}$ \\
\hline & Neurovoz corpus & NA & 32 & 20 & 27 & 29 & [74] \\
\hline & $\begin{array}{l}\text { PPMI (Parkinson Progression } \\
\text { Markers Initiative) database } \\
(n=14)\end{array}$ & MRI Machine & \multicolumn{2}{|c|}{129} & \multicolumn{2}{|r|}{57} & $\begin{array}{l}{[20,28,41,47,59,66,67,} \\
76,82,86,88,90,94,95]\end{array}$ \\
\hline & $\begin{array}{l}\text { The NTUA Parkinson Dataset } \\
\qquad(n=1)\end{array}$ & DaTscan and MRI Machine & \multicolumn{2}{|c|}{55} & \multicolumn{2}{|r|}{23} & [99] \\
\hline & $\begin{array}{l}\text { PC-GITA database } \\
\quad(n=1)\end{array}$ & Professional audio card & 25 & 25 & 25 & 25 & {$[50]$} \\
\hline & $\begin{array}{l}\text { Department of Neurology in } \\
\text { Cerrahpasa Faculty of Medicine, } \\
\text { Istanbul University } \\
(n=1)\end{array}$ & $\begin{array}{l}\text { Wacom Cintiq 12WX } \\
\text { graphics tablet }\end{array}$ & \multicolumn{2}{|c|}{57} & \multicolumn{2}{|r|}{15} & [101] \\
\hline & $\begin{array}{l}\text { HandPD dataset } \\
\text { Botucatu Medical School, São Paulo } \\
\text { State University } \\
(n=2)\end{array}$ & Smartphone Camera & 59 & 15 & \multicolumn{2}{|r|}{12} & {$[19,102]$} \\
\hline & $\begin{array}{c}\text { Daphnet Dataset } \\
\text { University of California, } \\
\text { Irvine Machine Learning repository } \\
(n=2)\end{array}$ & $\begin{array}{l}\text { sensor was attached to a belt } \\
\text { and above the ankle } \\
\text { and above the knee }\end{array}$ & 7 & 3 & NA & NA & {$[62,65]$} \\
\hline & $\begin{array}{l}\text { Parkinsons drawing spirals } \\
\text { and waves } \\
\text { Kaggle }\end{array}$ & $\begin{array}{l}\text { Tablet for capture } \\
\text { the drawing }\end{array}$ & \multicolumn{2}{|c|}{27} & \multicolumn{2}{|r|}{28} & {$[30,101]$} \\
\hline
\end{tabular}

Biometric signal and time-sensor-based dataset were collected using the digital keyboard or sensor/accelerometer $(n=16)$ attached to the PD and healthy control sample or placed at a different angle to measure the severity of the freezing gait or the tremor. Moreover, devices such as a high-quality standalone microphone or smartphone were used to collect the biomedical voice dataset, and $(n=15)$ reported a public vocal dataset. Moreover, in the public dataset, only $(n=11)$ reported the gender of PD and healthy control sample, and only $(n=5)$ studies identified each sample's mean age.

\subsubsection{Private Dataset}

As mentioned, the earlier total number of private datasets $(n=31)$ is shown in Table 5 . We summarized the dataset that was clearly explained within studies $(n=5)$. This dataset was collected and labeled in different entities such as hospitals, universities, and research centers. The number of PD and healthy control samples are reported, including gender. Table 5 only provides a sample of the private datasets used within the included studies. The number of males in the PD sample is higher than the number of females, whereas the number of females in health control is higher than the number of males. Furthermore, different types of hardware devices were used to collect the dataset; we have noticed that most of the data were in the form of images collected with different devices, starting from hospital imaging device including MRI, CT, DaTscan and ending with smartphone images that were used to capture handwriting or drawing of the PD samples $(n=11)$. 
Table 5. Private dataset descriptions.

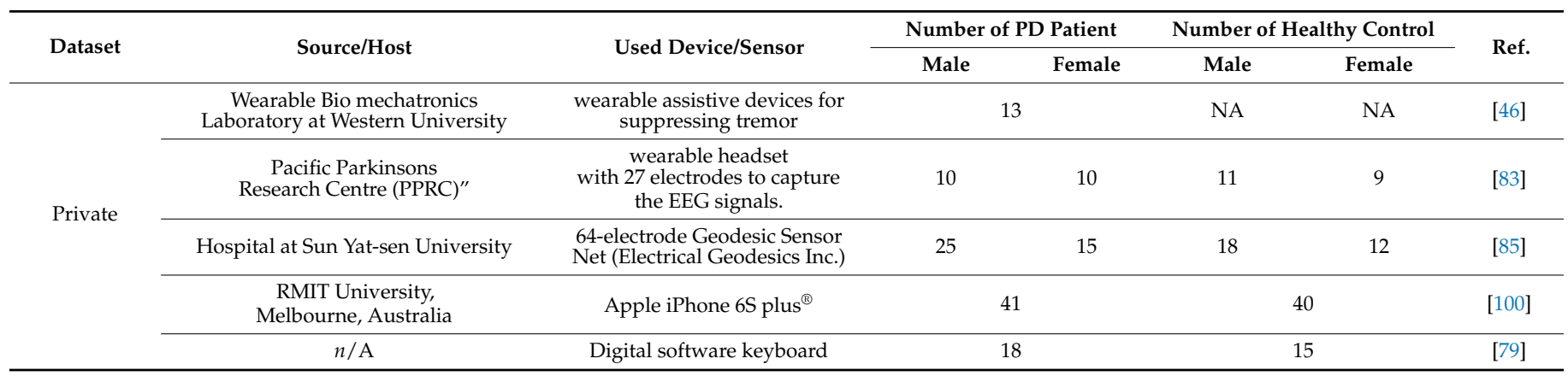

Biometric signal and time-serious-based dataset were collected using the digital keyboard or sensor/accelerometer $(n=14)$ attached to the PD and healthy control sample or placed at a different angle to measure the severity of the freezing gait or the tremor. Moreover, devices such as a high-quality standalone microphone or smartphone were used to collect the biomedical voice dataset, and $(n=6)$ reported a private vocal dataset. Moreover, in the private dataset, only $(n=4)$ reported the gender of PD and healthy control sample, and only $(n=4)$ studies identified each sample's mean age.

\section{Discussion}

\subsection{Principal Findings}

Although this study focuses on identifying and addressing deep learning and neural network application to detect Parkinson's disease in the early stage, we found some proposed models show promising results and can be employed in hospitals. This review provides recommendations for professional healthcare and researchers based on the included studies' outcomes. Moreover, we noticed that five studies $[21,37,49,55,81]$ used the Vertical Ground Reaction (VGRF) dataset, which was obtained from PhysioNet hub to train the classification models including fuzzy neural networks (FNNs), stacked 2D CNNs, deep neural networks (DNNs), artificial neural networks (ANNs), and neighborhood representation local binary pattern (NR-LBP). However, DNN in [49] surprisingly achieved outstanding results for early detection of PD using the VGRF dataset, compared to the other studies.

Furthermore, for imaging dataset including MRI, PET CT, and DaTSCAN were mainly obtained from Parkinson Progression Markers Initiative (PPMI) to train classifier, as seen in $[20,28,41,47,59,66,67,76,82,86,88,90,94,95]$; hence, among all studies, CNN in [20] and FNN in [28] achieved an outstanding result for image classification.

We found that most of the biomedical voice measurements dataset was obtained from the University of California (UCI) Irvine Machine Learning repository; in [53,84] and [23], the same dataset is used; however, 19 achieved outstanding result using the sequential model in a deep neural network for detection PD based on voice measurement. In [33,44], and [4], the same voice measurement datasets with 756 instances and 754 attributes were used to identify PD, and the autoencoder neural network in [33] achieved better results than other studies.

Electroencephalograph (EEG) dataset was obtained from a different source and used in five studies $[32,38,51,83,85]$. In [38,83], we found that long short-term memory (LSTM) achieved outstanding results, indicating the best option to deal with EEG data. On the other hand, seven studies $[3,19,25,27,40,69,101,102]$ focused on the classification of handwriting image to identify PD in the early stage, and we found that outstanding results were achieved in ANN + SVM in [3], dual-path RNN (DPRNN) in [40], and CNN + OptimumPath Forest (OPF) in [102], respectively.

As mentioned earlier, the detection of PD using a neural network is not an easier task than other types of diseases because PD symptoms (vocal disorder, tremor disorder, freezing gait disorder) are inconsistent, and it is difficult to collect data concerning the 
type of the device. Therefore, many public repositories mainly focus on collecting and process certain types of datasets. Moreover, based on our findings, we can conclude that the sequential model in DNN and autoencoder neural network proved to be suitable models for PD detection from speech. Moreover, DNN is recommended to identify PD from VGFR data. Additionally, CNN is still on top for medical image classification such as MRI, PET/CT, and DaTSCAN. Moreover, the FNN shows significant results in classifying a medical image. On the other hand, in regard to images of handwritings, we found that ANN with machine learning classifier SVM had a remarkable result for the identification of PD from handwriting.

Based on the findings of this review, we can highlight the most used repositories that contain PD public datasets for the research community as follows: (1) UCI Repository of Machine Learning Database, University of California; (2) PhysioNet Laboratory for Computational Physiology, Massachusetts Institute of Technology; (3) Parkinson's Progression Markers Initiative (PPMI); (4) Pacific Parkinson's Research Institute; and (5) Botucatu Medical School, São Paulo State University, Brazil.

\subsection{Strengths and Limitations}

\subsubsection{Strengths}

This review covered deep learning neural network techniques used for PD detection regardless of the characteristics, country, and study design. We claim that this review is a comprehensive study of neural network approaches used for PD detection. It will help researchers to understand how neural network is used efficiently for detecting PD in early stages. Compared with other reviews [106-108] that do not focus on PD disease, this review is unique in its field because it describes and summarizes features of the identified neural network models, datasets, available repository, type of PD evaluation, validation, and research implication. Moreover, this review is different from the previously mentioned reviews by following the latest version of PRISMA-ScR [16]. Unlike other reviews, we retrieved the studies from the most popular computer science and healthcare database to determine the most relevant studies possible.

\subsubsection{Limitations}

In the beginning, we carried out a primary search from 2015 to 2021 through the five selected databases, and we retrieved a massive number of studies. Therefore, we limited our search to the period between 2018 to 2021. Due to that, we may have missed some significant studies. Due to many studies that we included $(n=92)$, backward and forward reference checking was not performed in this review. PD is an extensive topic and divided into many types of diseases, including various symptoms. Therefore, we may have missed categorizing some diseases from a clinical perspective.

\subsection{Practical and Research Implications}

Although this review investigates the neural networks used to detect Parkinson's disease (PD), some applications could significantly mitigate this neurodegenerative disorder. Nowadays, computer-aided diagnosis systems are essential because they are less time consuming and more user friendly. For example, the authors of [51] designed a GUI system that physicians may use for fast diagnosis of Parkinson's disease in its early stages. Researchers can also use the system to continue their future research on disease diagnosis, especially neurodegenerative disorders. The system will show the patient's disease progression and help clinicians monitor the disease in its early stages.

Furthermore, the system can differentiate between PD patients and healthy subjects and compare various parameters (EEG, EMG, MRI/PET scan). In both PD and control subjects, the model can detect the region of dopamine output in the substantia nigra. As a result, the proposed model would be a novel solution containing all of the PD detection parameters in a single window, which would be extremely useful for disease monitoring. 
In the included studies $[6,18,19,30,61,75,87,91,92,96,98,101]$, clinicians could obtain PD Patient data in telemonitoring using devices such as tablets and smartphones. It is a promising solution because they can increase monitoring frequency without putting a strain on professional resources during the COVID-19 pandemic. However, the cost of training and testing the detection algorithm on a smartphone was too high; thus, the results were measured on a remote server and then transferred to the computer.

Clinical studies can refer to a video recorded for the patient while performing physical activities such as a PD bed test. As mentioned, in $[18,43,70,87]$, a neural network was able to identify the symptoms of PD through a video sample of the patient. In the future, the clinical studies may analyze any video recorded in the hospital for other patients, for example, during therapy sessions, and predict if this patient is suspected of having PD in the future.

\section{Conclusions}

This scoping review summarized studies by investigating the use of neural networks, specifically deep learning algorithms, for early diagnosis of PD based on various data collected from different public and private sources (91 studies), including medical image, biomedical voice, and sensor signal, for both PD and healthy control samples. Included studies were categorized into different groups based on the neural network model, type of PD symptoms, and type of dataset. Additionally, the most used dataset and best performance model were highlighted based on the detection of particular symptoms of PD in this review. All technical experiment methods were reported, including submodel, dataset volume, training, testing, evaluation metrics, and validation type. We indicated any real-time implementation used in each hospital or university setting, and based on this review, we recommended particular suggestions for healthcare professionals. Future work could be a meta-analysis to examine each study and provide a comprehensive comparison between them in terms of quality.

Author Contributions: Conceptualization, formal analysis, methodology, and writing-original draft, M.S.A., U.S. and K.D.; Data curation and investigation, A.A.A.-A. and A.A.; Writing-review \& editing, H.D.Z.; Supervision and validation, M.H. All authors have read and agreed to the published version of this manuscript.

Funding: This research received no external funding.

Institutional Review Board Statement: Not applicable.

Data Availability Statement: Not applicable.

Conflicts of Interest: The authors declare no conflict of interest.

$\begin{array}{ll}\text { Abbreviations } \\ \text { PD } & \text { Parkinson's disease } \\ \text { FoG } & \text { Freezing of gait } \\ \text { NA } & \text { Not Available } \\ \text { MRI } & \text { Magnetic Resonance Imaging } \\ \text { PET } & \text { Positron emission tomography } \\ \text { CT } & \text { Computerized tomography } \\ \text { EEG } & \text { Electroencephalogram } \\ \text { EMG } & \text { Electromyography } \\ \text { VGRF } & \text { Vertical Ground Reaction Force } \\ \text { CNN } & \text { Convolutional Neural Network } \\ \text { RNN } & \text { Recurrent Neural Network } \\ \text { ANN } & \text { Artificial Neural Network } \\ \text { FNN } & \text { Fuzzy Neural Network } \\ \text { NN } & \text { Neural Network } \\ \text { DBN } & \text { Deep belief network }\end{array}$




$\begin{array}{ll}\text { MOGA } & \text { Multi-Objective Genetic Algorithm } \\ \text { BiLSTM } & \text { Bidirectional Long short-term memory } \\ \text { LSTM } & \text { Long short-term memory } \\ \text { OPF } & \text { Optimum-Path Forest } \\ \text { FRP } & \text { Fuzzy Recurrence Plot } \\ \text { DCNN } & \text { Deep Convolutional Neural Network } \\ \text { FCNN } & \text { Fully Connected-Neural Network } \\ \text { DNN } & \text { Deep Neural Network } \\ \text { EFMMOneR } & \text { Fuzzy Minmax Neural Network with The One R Attribute Evaluator } \\ \text { LRNN } & \text { Layer Recurrent Neural Network } \\ \text { MTL } & \text { Multi-Task Learning } \\ \text { GCN } & \text { Graph Convolutional Network } \\ \text { GS-RNN } & \text { Gradient Stabilized Recurrent Neural Network } \\ \text { NR-LBP } & \text { Neighborhood Representation Local Binary Pattern } \\ \text { TCN } & \text { Temporal Convolutional Neural network } \\ \text { WGAN } & \text { Wasserstein Generative Adversarial Networks } \\ \text { SAE } & \text { Stacked Auto Encoder } \\ \text { SSAE } & \text { Stacked Sparse Auto-Encoder } \\ \text { LSVRC } & \text { Large Scale Visual Recognition Challenge } \\ \text { DNMLDM } & \text { Deep Neural Mapping Large Margin Distribution Machine } \\ \text { MLP } & \text { Multiple Layer Perceptron } \\ \text { SVM } & \text { Support Vector Machine } \\ \text { SSM-PCA } & \text { Scaled Subprofile Modeling Using Principal Component Analysis } \\ \text { SNN } & \text { Siamese Neural Network } \\ \text { FCV } & \text { Fold-Cross Validation } \\ \text { LOOCV } & \text { Leave-One-Out Cross-Validation } \\ \text { LOSO } & \text { Leave One Subject Out } \\ \text { AUC } & \text { Area Under Curve }\end{array}$

\section{Appendix A}

Table A1. Used search terms and total number of retrieved studies per database.

\begin{tabular}{|c|c|c|}
\hline Database Name & Used Research Terms & $\begin{array}{c}\text { Number of } \\
\text { Retrieved Studies }\end{array}$ \\
\hline PubMed & 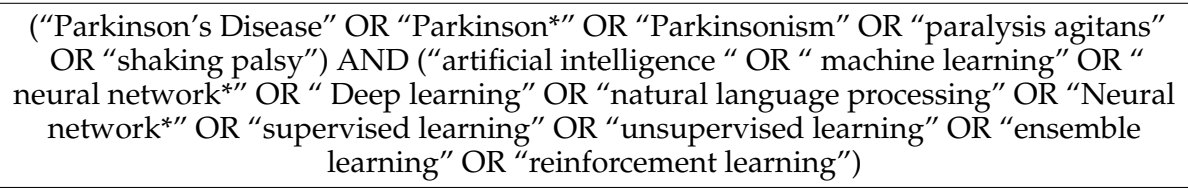 & 549 \\
\hline IEEE & 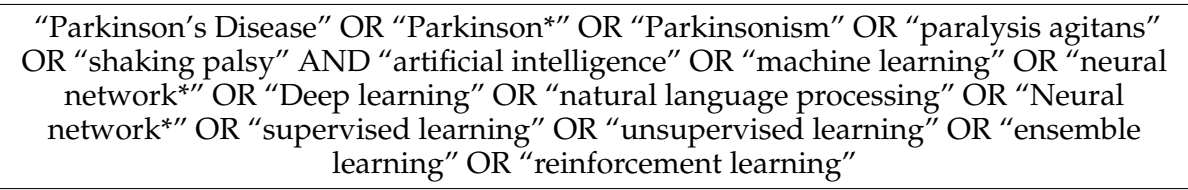 & 303 \\
\hline $\mathrm{ACM}$ & $\begin{array}{c}\text { ("Parkinson's Disease" OR “Parkinson*" OR "Parkinsonism" OR "paralysis agitans" } \\
\text { OR "shaking palsy") AND ("artificial intelligence" OR "machine learning" OR "neural } \\
\text { network*” OR “Deep learning" OR "natural language processing" OR “Neural } \\
\text { network" OR "supervised learning" OR "unsupervised learning" OR "ensemble } \\
\text { learning" OR "reinforcement learning") }\end{array}$ & 19 \\
\hline Science Direct & $\begin{array}{c}\text { (“Parkinson's Disease" OR “Parkinson” OR “Parkinsonism” OR “paralysis agitans” } \\
\text { OR “shaking palsy") AND ("artificial intelligence" OR "machine learning" OR "neural } \\
\text { network" OR “Deep learning”) }\end{array}$ & 151 \\
\hline Google Scholar & 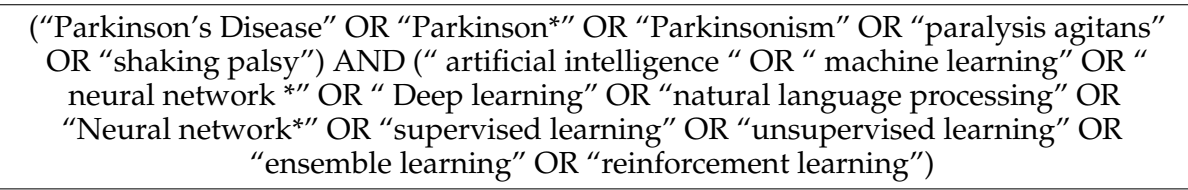 & 39 \\
\hline & Total studies 2018-2021 & 1061 \\
\hline
\end{tabular}




\section{Appendix B}

Table A2. Data extraction form.

\begin{tabular}{|c|c|}
\hline Concept & Definition \\
\hline \multicolumn{2}{|l|}{ Study Characteristics } \\
\hline Author & The first author of the study. \\
\hline Year Submission & The year in which the study was submitted. \\
\hline Country of publication & The country where the study was published. \\
\hline Publication type & The paper type (i.e., peer-reviewed, conference or preprint). \\
\hline \multicolumn{2}{|l|}{ AI technique characteristics } \\
\hline Purpose/use of AI & $\begin{array}{l}\text { What are the applications or uses of } \mathrm{AI} \text { in diagnosis of Parkinson (e.g., diagnosis, } \\
\text { classification, and detection)? }\end{array}$ \\
\hline AI branches & $\begin{array}{l}\text { The branches/areas that were used (e.g., traditional machine learning, deep learning, } \\
\text { natural language processing). }\end{array}$ \\
\hline AI models/algorithms & $\begin{array}{l}\text { The specific AI models or algorithms that were used (e.g., Decision tree, Random } \\
\text { forest, Convolutional neural network). }\end{array}$ \\
\hline \multicolumn{2}{|l|}{ Dataset Characteristics } \\
\hline Data sources & $\begin{array}{l}\text { Source of data that were used for the development and validation of } \\
\text { AI models/algorithms (e.g., public databases, clinical settings, government sources). }\end{array}$ \\
\hline Data types & $\begin{array}{l}\text { Type of data that were used for the development and validation of AI } \\
\text { models/algorithms (e.g., radiology images, biological data, laboratory data). }\end{array}$ \\
\hline Dataset size & $\begin{array}{l}\text { The total number of data that were used for the development and validation of AI } \\
\text { models/algorithms. }\end{array}$ \\
\hline Type of validation & $\begin{array}{l}\text { How the dataset was split/used to develop and test the proposed models/algorithms } \\
\text { (e.g., Train-test split, K-fold cross-validation, External validation). }\end{array}$ \\
\hline Proportion of training set & Percentage of the training set of the total dataset. \\
\hline Proportion of validation set & Percentage of validation set of the total dataset. \\
\hline Proportion of test set & Percentage of the test set of the total dataset. \\
\hline Type of device & The device used to collect the data (e.g., accelerometer, smartphone, etc.) \\
\hline At-risk group & The number of Parkinson's participants included in the study. \\
\hline Control group & The number of healthy participants included in the study \\
\hline
\end{tabular}

\section{References}

1. Alissa, M. Parkinson's Disease Diagnosis Using Deep Learning. arXiv 2021, arXiv:2101.05631.

2. Burke, R.E.; O'Malley, K. Axon degeneration in Parkinson's disease. Exp. Neurol. 2013, 246, 72-83. [CrossRef]

3. Ranjan, A.; Swetapadma, A. An Intelligent Computing Based Approach for Parkinson Disease Detection. In Proceedings of the Proceedings of 2018 2nd International Conference on Advances in Electronics, Computers and Communications, ICAECC 2018, Bangalore, India, 9-10 February 2018. [CrossRef]

4. Gunduz, H. Deep Learning-Based Parkinson's Disease Classification Using Vocal Feature Sets. IEEE Access 2019, 7, 115540-115551. [CrossRef]

5. “GBD Compare" Data Visualizations. Available online: https:/ /vizhub.healthdata.org/gbd-compare/ (accessed on 26 May 2021).

6. Quan, C.; Ren, K.; Luo, Z. A Deep Learning Based Method for Parkinson's Disease Detection Using Dynamic Features of Speech. IEEE Access 2021, 9, 10239-10252. [CrossRef]

7. Rana, A.Q.; Ahmed, U.S.; Chaudry, Z.M.; Vasan, S. Parkinson's disease: A review of non-motor symptoms. Expert Rev. Neurother. 2015, 15, 549-562. [CrossRef]

8. Sveinbjornsdottir, S. The clinical symptoms of Parkinson's disease. J. Neurochem. 2016, 139, 318-324. [CrossRef]

9. “Diagnosis Parkinson's Disease" NHS Choices. Available online: https://www.nhs.uk/conditions/parkinsons-disease/ diagnosis / (accessed on 26 May 2021).

10. Parkinson's Disease Information Page. National Institute of Neurological Disorders and Stroke; U.S. Department of Health and Human Services: Washington, DC, USA, 2020. 
11. Belić, M.; Bobić, V.; Badža, M.; Šolaja, N.; Đurić-Jovičić, M.; Kostić, V.S. Artificial intelligence for assisting diagnostics and assessment of Parkinson's disease-A review. Clin. Neurol. Neurosurg. 2019, 184, 105442. [CrossRef]

12. Sibley, K.G.; Girges, C.; Hoque, E.; Foltynie, T. Video-Based Analyses of Parkinson's Disease Severity: A Brief Review. J. Parkinsons. Dis. 2021, 1-11. [CrossRef]

13. Varrecchia, T.; Castiglia, S.F.; Ranavolo, A.; Conte, C.; Tatarelli, A.; Coppola, G.; Di Lorenzo, C.; Draicchio, F.; Pierelli, F.; Serrao, M. An artificial neural network approach to detect presence and severity of Parkinson's disease via gait parameters. PLoS ONE 2021, 16, e0244396. [CrossRef]

14. Khachnaoui, H.; Mabrouk, R.; Khlifa, N. Machine learning and deep learning for clinical data and PET/SPECT imaging in Parkinson's disease: A review. IET Image Process. 2020, 14, 4013-4026. [CrossRef]

15. Maclagan, L.C.; Visanji, N.P.; Cheng, Y.; Tadrous, M.; Lacoste, A.M.; Kalia, L.V.; Marras, C. Identifying drugs with diseasemodifying potential in Parkinson's disease using artificial intelligence and pharmacoepidemiology. Wiley Online Libr. 2020, 29, 864-872. [CrossRef] [PubMed]

16. Tricco, A.C.; Lillie, E.; Zarin, W.; O’Brien, K.K.; Colquhoun, H.; Levac, D.; Moher, D.; Peters, M.D.J.; Horsley, T.; Weeks, L.; et al. PRISMA extension for scoping reviews (PRISMA-ScR): Checklist and explanation. Ann. Intern. Med. 2018, 169, 467-473. [CrossRef] [PubMed]

17. Ouzzani, M.; Hammady, H.; Fedorowicz, Z.; Elmagarmid, A. Rayyan-a web and mobile app for systematic reviews. Syst. Rev. 2016, 5, 1-10. [CrossRef]

18. Ali, M.R.; Hernandez, J.; Dorsey, E.R.; Hoque, E.; McDuff, D. Spatio-Temporal Attention and Magnification for Classification of Parkinson's Disease from Videos Collected via the Internet. In Proceedings of the 2020 15th IEEE International Conference on Automatic Face and Gesture Recognition (FG 2020); IEEE: New York, NY, USA, 2020; pp. 207-214. [CrossRef]

19. Gazda, M.; Hires, M.; Drotar, P. Multiple-Fine-Tuned Convolutional Neural Networks for Parkinson's Disease Diagnosis from Offline Handwriting. IEEE Trans. Syst. Man, Cybern. Syst. 2021, 1-12. [CrossRef]

20. Mohammed, F.; He, X.; Lin, Y. An easy-to-use deep-learning model for highly accurate diagnosis of Parkinson's disease using SPECT images. Comput. Med. Imaging Graph. 2021, 87, 101810. [CrossRef]

21. Aversano, L.; Bernardi, M.L.; Cimitile, M.; Pecori, R. Fuzzy neural networks to detect parkinson disease. In Proceedings of the 2020 IEEE International Conference on Fuzzy Systems (FUZZ-IEEE), Glasgow, UK, 19-24 July 2020; pp. 1-8. [CrossRef]

22. Abayomi-Alli, O.O.; Damasevicius, R.; Maskeliunas, R.; Abayomi-Alli, A. BiLSTM with Data Augmentation using Interpolation Methods to Improve Early Detection of Parkinson Disease. In Proceedings of the 2020 Federated Conference on Computer Science and Information Systems, FedCSIS 2020, Sofia, Bulgaria, 6-9 September 2020; Polish Information Processing Society PTI: Warsaw, Poland, 2020; Volume 21, pp. 371-380. [CrossRef]

23. Asmae, O.; Abdelhadi, R.; Bouchaib, C.; Sara, S.; Tajeddine, K. Parkinson's Disease Identification using KNN and ANN Algorithms based on Voice Disorder. In Proceedings of the 2020 1st International Conference on Innovative Research in Applied Science, Engineering and Technology, IRASET 2020, Meknes, Morocco, 16-19 April 2020; IEEE: New York, NY, USA, 2020. [CrossRef]

24. Tuan, A.M.; Andrei, A.G.; Ionescu, B. Freezing of gait detection for parkinson's disease patients using accelerometer data: Case study. In Proceedings of the 2020 8th E-Health and Bioengineering Conference, EHB 2020, Iasi, Romania, 29-30 October 2020; IEEE: New York, NY, USA, 2020. [CrossRef]

25. Aghzal, M.; Mourhir, A. Early Diagnosis of Parkinson's Disease based on Handwritten Patterns using Deep Learning. In Proceedings of the 4th International Conference on Intelligent Computing in Data Sciences, ICDS 2020, Fez, Morocco, 21-23 October 2020; IEEE: New York, NY, USA, 2020. [CrossRef]

26. Moshkova, A.; Samorodov, A.; Ivanova, E.; Fedotova, E. High Accuracy Discrimination of Parkinson's Disease from Healthy Controls by Hand Movements Analysis Using LeapMotion Sensor and 1D Convolutional Neural Network. In Proceedings of the Proceedings-2020 Ural Symposium on Biomedical Engineering, Radioelectronics and Information Technology, USBEREIT 2020, Yekaterinburg, Russia, 14-15 May 2020; IEEE: New York, NY, USA, 2020; pp. 62-65. [CrossRef]

27. Shaban, M. Deep Convolutional Neural Network for Parkinson's Disease Based Handwriting Screening. In Proceedings of the ISBI Workshops 2020-International Symposium on Biomedical Imaging Workshops, Iowa City, IA, USA, 4 April 2020; IEEE: New York, NY, USA, 2020. [CrossRef]

28. Wang, W.; Lee, J.; Harrou, F.; Sun, Y. Early Detection of Parkinson's Disease Using Deep Learning and Machine Learning. IEEE Access 2020, 8, 147635-147646. [CrossRef]

29. Suhas, B.N.; Mallela, J.; Illa, A.; Yamini, B.K.; Atchayaram, N.; Yadav, R.; Gope, D.; Ghosh, P.K. Speech task based automatic classification of ALS and Parkinson's Disease and their severity using log Mel spectrograms. In Proceedings of the SPCOM 2020-International Conference on Signal Processing and Communications, Bangalore, India, 19-24 July 2020; IEEE: New York, NY, USA, 2020. [CrossRef]

30. Chakraborty, S.; Aich, S.; Sim, J.-S.; Han, E.; Park, J.; Kim, H.C. Parkinson's Disease Detection from Spiral and Wave Drawings using Convolutional Neural Networks: A Multistage Classifier Approach. In Proceedings of the International Conference on Advanced Communication Technology, ICACT, Phoenix Park, Korea, 16-19 February 2020; IEEE: New York, NY, USA, 2020; Volume 2020, pp. 298-303. [CrossRef]

31. Shreya Prabhu, K.; Joy Martis, R. Diagnosis of Parkinson's Disease using Computer Aided Tool based on EEG. In Proceedings of the 2020 IEEE 17th India Council International Conference, INDICON 2020, New Delhi, India, 10-13 December 2020; IEEE: New York, NY, USA, 2020; pp. 1-4. [CrossRef] 
32. Oh, S.L.; Hagiwara, Y.; Raghavendra, U.; Yuvaraj, R.; Arunkumar, N.; Murugappan, M.; Acharya, U.R. A deep learning approach for Parkinson's disease diagnosis from EEG signals. Neural Comput. Appl. 2020, 32, 10927-10933. [CrossRef]

33. Xiong, Y.; Lu, Y. Deep Feature Extraction from the Vocal Vectors Using Sparse Autoencoders for Parkinson's Classification. IEEE Access 2020, 8, 27821-27830. [CrossRef]

34. Ashour, A.S.; El-Attar, A.; Dey, N.; El-Kader, H.A.; El-Naby, M.M.A. Long short term memory based patient-dependent model for FOG detection in Parkinson's disease. Pattern Recognit. Lett. 2020, 131, 23-29. [CrossRef]

35. El Maachi, I.; Bilodeau, G.-A.; Bouachir, W. Deep 1D-Convnet for accurate Parkinson disease detection and severity prediction from gait. Expert Syst. Appl. 2020, 143, 113075. [CrossRef]

36. Oktay, A.B.; Kocer, A. Differential diagnosis of Parkinson and essential tremor with convolutional LSTM networks. Biomed. Signal Process. Control. 2020, 56, 101683. [CrossRef]

37. Yurdakul, O.C.; Subathra, M.; George, S.T. Detection of Parkinson's Disease from gait using Neighborhood Representation Local Binary Patterns. Biomed. Signal Process. Control. 2020, 62, 102070. [CrossRef]

38. Shah, S.A.A.; Zhang, L.; Bais, A. Dynamical system based compact deep hybrid network for classification of Parkinson disease related EEG signals. Neural Networks 2020, 130, 75-84. [CrossRef] [PubMed]

39. Veeraragavan, S.; Gopalai, A.A.; Gouwanda, D.; Ahmad, S.A. Parkinson's Disease Diagnosis and Severity Assessment Using Ground Reaction Forces and Neural Networks. Front. Physiol. 2020, 11. [CrossRef] [PubMed]

40. Xu, S.; Wang, Z.; Sun, J.; Zhang, Z.; Wu, Z.; Yang, T.; Xue, G.; Cheng, C. Using a deep recurrent neural network with EEG signal to detect Parkinson's disease. Ann. Transl. Med. 2020, 8, 874. [CrossRef] [PubMed]

41. Chakraborty, S.; Aich, S.; Kim, H.-C. Detection of Parkinson's Disease from 3T T1 Weighted MRI Scans Using 3D Convolutional Neural Network. Diagn. 2020, 10, 402. [CrossRef]

42. Hu, K.; Wang, Z.; Wang, W.; Martens, K.A.E.; Wang, L.; Tan, T.; Lewis, S.J.G.; Feng, D.D. Graph Sequence Recurrent Neural Network for Vision-Based Freezing of Gait Detection. IEEE Trans. Image Process. 2019, 29, 1890-1901. [CrossRef] [PubMed]

43. Filtjens, B.; Nieuwboer, A.; D'Cruz, N.; Spildooren, J.; Slaets, P.; Vanrumste, B. A data-driven approach for detecting gait events during turning in people with Parkinson's disease and freezing of gait. Gait Posture 2020, 80, 130-136. [CrossRef]

44. Sarker, Y.; Mondal, N.I.; Fahim, S.R.; Shahriar, S.; Sarker, S.K.; Das, S.K. A Novel Diagnosis System Using Regularized EncoderDecoder Based Generative Probabilistic Network for Parkinson's Disease. In 2020 IEEE Region 10 Symposium (TENSYMP); IEEE: New York, NY, USA, 2020; pp. 1444-1447. [CrossRef]

45. Ibrahim, A.; Zhou, Y.; Jenkins, M.E.; Trejos, A.L.; Naish, M.D. The Design of a Parkinson's Tremor Predictor and Estimator Using a Hybrid Convolutional-Multilayer Perceptron Neural Network. In Proceedings of the 2020 42nd Annual International Conference of the IEEE Engineering in Medicine \& Biology Society (EMBC), Montreal, QC, Canada, 20-24 July 2020; IEEE: New York, NY, USA, 2020; Volume 2020, pp. 5996-6000. [CrossRef]

46. Ibrahim, A.; Zhou, Y.; Jenkins, M.E.; Naish, M.D.; Trejos, A.L. Parkinson's Tremor Onset Detection and Active Tremor Classification Using a Multilayer Perceptron. In Proceedings of the 2020 IEEE Canadian Conference on Electrical and Computer Engineering (CCECE), London, ON, Canada, 30 August-2 September 2020; IEEE: New York, NY, USA, 2020; pp. 1-4. [CrossRef]

47. Ramirez, V.M.; Kmetzsch, V.; Forbes, F.; Dojat, M. Deep Learning Models to Study the Early Stages of Parkinson's Disease. In Proceedings of the 2020 IEEE 17th International Symposium on Biomedical Imaging (ISBI), Iowa City, IA, USA, 3-7 April 2020; IEEE: New York, NY, USA, 2020; pp. 1534-1537. [CrossRef]

48. Bielby, J.; Kuhn, S.; Colreavy-Donnelly, S.; Caraffini, F.; O'Connor, S.; Anastassi, Z.A. Identifying Parkinson's Disease Through the Classification of Audio Recording Data. In Proceedings of the 2020 IEEE Congress on Evolutionary Computation (CEC), Glasgow, UK, 19-24 July 2020; IEEE: New York, NY, USA, 2020; pp. 1-7. [CrossRef]

49. Aversano, L.; Bernardi, M.L.; Cimitile, M.; Pecori, R. Early Detection of Parkinson Disease using Deep Neural Networks on Gait Dynamics. In Proceedings of the 2020 International Joint Conference on Neural Networks (IJCNN), Glasgow, UK, 19-24 July 2020; IEEE: New York, NY, USA, 2020; pp. 1-8. [CrossRef]

50. Karan, B.; Sahu, S.S.; Mahto, K. Stacked auto-encoder based Time- frequency features of Speech signal for Parkinson disease prediction. In Proceedings of the 2020 International Conference on Artificial Intelligence and Signal Processing (AISP), Amaravati, India, 10-12 January 2020; IEEE: New York, NY, USA, 2020; pp. 1-4. [CrossRef]

51. Saikia, A.; Majhi, V.; Hussain, M.; Barua, A.R.; Paul, S.; Verma, J.K. Machine Learning based Diagnostic System for Early Detection of Parkinson's Disease. In Proceedings of the 2020 International Conference on Computational Performance Evaluation (ComPE), Shillong, India, 2-4 July 2020; IEEE: New York, NY, USA, 2020; pp. 275-279. [CrossRef]

52. Ali, L.; Zhu, C.; Zhang, Z.; Liu, Y. Automated Detection of Parkinson's Disease Based on Multiple Types of Sustained Phonations Using Linear Discriminant Analysis and Genetically Optimized Neural Network. IEEE J. Transl. Eng. Heal. Med. 2019, 7, 1-10. [CrossRef]

53. Haq, A.U.; Li, J.; Memon, M.H.; Khan, J.; Din, S.U.; Ahad, I.; Sun, R.; Lai, Z. Comparative Analysis of the Classification Performance of Machine Learning Classifiers and Deep Neural Network Classifier for Prediction of Parkinson Disease. In Proceedings of the 2018 15th International Computer Conference on Wavelet Active Media Technology and Information Processing (ICCWAMTIP), Chengdu, China, 14-16 December 2018; IEEE: New York, NY, USA, 2018; pp. 101-106. [CrossRef]

54. Kollia, I.; Stafylopatis, A.-G.; Kollias, S. Predicting Parkinson's Disease using Latent Information extracted from Deep Neural Networks. In Proceedings of the 2019 International Joint Conference on Neural Networks (IJCNN), Budapest, Hungary, 14-19 July 2019; IEEE: New York, NY, USA, 2019; pp. 1-8. [CrossRef] 
55. Shivangi; Johri, A.; Tripathi, A. Parkinson Disease Detection Using Deep Neural Networks. In Proceedings of the 2019 Twelfth International Conference on Contemporary Computing (IC3), Noida, India, 8-10 August 2019; IEEE: New York, NY, USA, 2019; pp. 1-4. [CrossRef]

56. Giuliano, M.; Garcia-Lopez, A.; Perez, S.; Perez, F.D.; Spositto, O.; Bossero, J. Selection of voice parameters for Parkinson's disease prediction from collected mobile data. In Proceedings of the 2019 XXII Symposium on Image, Signal Processing and Artificial Vision (STSIVA), Bucaramanga, Colombia, 24-26 April 2019; IEEE: New York, NY, USA, 2019; pp. 1-3. [CrossRef]

57. Tahafchi, P.; Judy, J.W. Freezing-of-Gait Detection Using Wearable-Sensor Technology and Neural-Network Classifier. In Proceedings of the 2019 IEEE Sensors Applications Symposium (SAS), Montreal, QC, Canada, 27-30 October 2019; IEEE: New York, NY, USA, 2019; pp. 1-4. [CrossRef]

58. Yagis, E.; De Herrera, A.G.S.; Citi, L. Generalization Performance of Deep Learning Models in Neurodegenerative Disease Classification. In Proceedings of the 2019 IEEE International Conference on Bioinformatics and Biomedicine (BIBM), San Diego, CA, USA, 18-21 November 2019; IEEE: New York, NY, USA, 2019; pp. 1692-1698. [CrossRef]

59. Rumman, M.; Tasneem, A.N.; Farzana, S.; Pavel, M.I.; Alam, A. Early detection of Parkinson's disease using image processing and artificial neural network. In Proceedings of the 2018 Joint 7th International Conference on Informatics, Electronics \& Vision (ICIEV) and 2018 2nd International Conference on Imaging, Vision \& Pattern Recognition (icIVPR), Kitakyushu, Japan, 25-29 June 2018; IEEE: New York, NY, USA, 2018; pp. 256-261. [CrossRef]

60. Anand, A.; Haque, A.; Alex, J.S.R.; Venkatesan, N. Evaluation of Machine learning and Deep learning algorithms combined with dimentionality reduction techniques for classification of Parkinson's Disease. In Proceedings of the 2018 IEEE International Symposium on Signal Processing and Information Technology (ISSPIT), Louisville, KY, USA, 6-8 December 2018; IEEE: New York, NY, USA, 2018; pp. 342-347. [CrossRef]

61. Wroge, T.J.; Ozkanca, Y.; Demiroglu, C.; Si, D.; Atkins, D.C.; Ghomi, R.H. Parkinson's Disease Diagnosis Using Machine Learning and Voice. In Proceedings of the 2018 IEEE Signal Processing in Medicine and Biology Symposium (SPMB), Philadelphia, PA, USA, 1 December 2018; IEEE: New York, NY, USA, 2018; pp. 1-7. [CrossRef]

62. Arami, A.; Poulakakis-Daktylidis, A.; Tai, Y.F.; Burdet, E. Prediction of Gait Freezing in Parkinsonian Patients: A Binary Classification Augmented With Time Series Prediction. IEEE Trans. Neural Syst. Rehabilitation Eng. 2019, 27, 1909-1919. [CrossRef]

63. Pandit, T.; Nahane, H.; Lade, D.; Rao, V. Abnormal Gait Detection by Classifying Inertial Sensor Data using Transfer Learning. In Proceedings of the 2019 18th IEEE International Conference On Machine Learning And Applications (ICMLA), Boca Raton, FL, USA, 16-19 December 2019; IEEE: New York, NY, USA, 2019; pp. 1444-1447. [CrossRef]

64. Fernandes, C.; Fonseca, L.; Ferreira, F.; Gago, M.; Costa, L.; Sousa, N.; Ferreira, C.; Gama, J.; Erlhagen, W.; Bicho, E. Artificial Neural Networks Classification of Patients with Parkinsonism based on Gait. In Proceedings of the 2018 IEEE International Conference on Bioinformatics and Biomedicine (BIBM), Madrid, Spain, 3-6 December 2018; IEEE: New York, NY, USA, 2018; pp. 2024-2030. [CrossRef]

65. Torvi, V.G.; Bhattacharya, A.; Chakraborty, S. Deep Domain Adaptation to Predict Freezing of Gait in Patients with Parkinson's Disease. In Proceedings of the 2018 17th IEEE International Conference on Machine Learning and Applications (ICMLA), Orlando, FL, USA, 17-20 December 2018; IEEE: New York, NY, USA, 2018; pp. 1001-1006. [CrossRef]

66. Zhang, X.; Yang, Y.; Wang, H.; Ning, S.; Wang, H. Deep Neural Networks with Broad Views for Parkinson's Disease Screening. In Proceedings of the 2019 IEEE International Conference on Bioinformatics and Biomedicine (BIBM), San Diego, CA, USA, 18-21 November 2019; IEEE: New York, NY, USA, 2019; pp. 1018-1022. [CrossRef]

67. Dai, Y.; Tang, Z.; Wang, Y.; Xu, Z. Data Driven Intelligent Diagnostics for Parkinson's Disease. IEEE Access 2019, 7, 106941-106950. [CrossRef]

68. Abdallah, M.; Saad, A.; Ayache, M. Freezing of Gait Detection: Deep Learning Approach. In Proceedings of the 2019 International Arab Conference on Information Technology (ACIT), Al Ain, United Arab Emirates, 3-5 December 2019; IEEE: New York, NY, USA, 2019; pp. 259-261. [CrossRef]

69. Taleb, C.; Khachab, M.; Mokbel, C.; Likforman-Sulem, L. Visual Representation of Online Handwriting Time Series for Deep Learning Parkinson's Disease Detection. In Proceedings of the 2019 International Conference on Document Analysis and Recognition Workshops (ICDARW), Sydney, NSW, Australia, 22-25 September 2019; IEEE: New York, NY, USA, 2019; Volume 6, pp. 25-30. [CrossRef]

70. Reyes, J.F.; Montealegre, J.S.; Castano, Y.J.; Urcuqui, C.; Navarro, A. LSTM and Convolution Networks exploration for Parkinson's Diagnosis. In Proceedings of the 2019 IEEE Colombian Conference on Communications and Computing (COLCOM), Barranquilla, Colombia, 5-7 June 2019; IEEE: New York, NY, USA, 2019; pp. 1-4. [CrossRef]

71. Zhao, Y.; Cumming, P.; Rominger, A.; Zuo, C.; Shi, K.; Wu, P.; Wang, J.; Li, H.; Navab, N.; Yakushev, I.; et al. A 3D Deep Residual Convolutional Neural Network for Differential Diagnosis of Parkinsonian Syndromes on 18F-FDG PET Images. In Proceedings of the 2019 41st Annual International Conference of the IEEE Engineering in Medicine and Biology Society (EMBC), Berlin, Germany, 23-27 July 2019; IEEE: New York, NY, USA, 2019; Volume 2019, pp. 3531-3534. [CrossRef]

72. Kiryu, S.; Yasaka, K.; Akai, H.; Nakata, Y.; Sugomori, Y.; Hara, S.; Seo, M.; Abe, O.; Ohtomo, K. Deep learning to differentiate parkinsonian disorders separately using single midsagittal MR imaging: A proof of concept study. Eur. Radiol. 2019, 29, 6891-6899. [CrossRef] [PubMed] 
73. Sadek, R.M.; Mohammed, S.A.; Abunbehan, A.R.K.; Ghattas, A.K.H.A.; Badawi, M.R.; Mortaja, M.N.; Abu-Naser, S.S. Parkinson's Disease Prediction Using Artificial Neural Network. Comput. Sci. 2019, 3, 1-8. Available online: http:/ / dstore.alazhar.edu.ps/ xmlui/handle/123456789/302 (accessed on 26 May 2021).

74. Bhati, S.; Velazquez, L.M.; Villalba, J.; Dehak, N. LSTM Siamese Network for Parkinson's Disease Detection from Speech. In Proceedings of the 2019 IEEE Global Conference on Signal and Information Processing (GlobalSIP), Ottawa, ON, Canada, 11-14 November 2019; IEEE: New York, NY, USA, 2019; pp. 1-5. [CrossRef]

75. Afonso, L.C.; Rosa, G.H.; Pereira, C.R.; Weber, S.A.; Hook, C.; Albuquerque, V.H.C.; Papa, J.P. A recurrence plot-based approach for Parkinson's disease identification. Futur. Gener. Comput. Syst. 2019, 94, 282-292. [CrossRef]

76. Ortiz, A.; Munilla, J.; Martínez-Ibañez, M.; Górriz, J.M.; Ramírez, J.; Salas-Gonzalez, D. Parkinson's Disease Detection Using Isosurfaces-Based Features and Convolutional Neural Networks. Front. Aging Neurosci. 2019, 13, 48. [CrossRef] [PubMed]

77. Wodzinski, M.; Skalski, A.; Hemmerling, D.; Orozco-Arroyave, J.R.; Noth, E. Deep Learning Approach to Parkinson's Disease Detection Using Voice Recordings and Convolutional Neural Network Dedicated to Image Classification. In Proceedings of the 2019 41st Annual International Conference of the IEEE Engineering in Medicine and Biology Society (EMBC), Berlin, Germany, 23-27 July 2019; IEEE: New York, NY, USA, 2019; Volume 2019, pp. 717-720. [CrossRef]

78. Manzanera, O.M.; Meles, S.K.; Leenders, K.L.; Renken, R.J.; Pagani, M.; Arnaldi, D.; Nobili, F.; Obeso, J.; Oroz, M.R.; Morbelli, S.; et al. Scaled Subprofile Modeling and Convolutional Neural Networks for the Identification of Parkinson's Disease in 3D Nuclear Imaging Data. Int. J. Neural Syst. 2019, 29, 1950010. [CrossRef] [PubMed]

79. Iakovakis, D.; Diniz, J.A.; Trivedi, D.; Chaudhuri, R.K.; Hadjileontiadis, L.J.; Hadjidimitriou, S.; Charisis, V.; Bostanjopoulou, S.; Katsarou, Z.; Klingelhoefer, L.; et al. Early Parkinson's Disease Detection via Touchscreen Typing Analysis using Convolutional Neural Networks. In Proceedings of the 2019 41st Annual International Conference of the IEEE Engineering in Medicine and Biology Society (EMBC), Berlin, Germany, 23-27 July 2019; IEEE: New York, NY, USA, 2019; Volume 2019, pp. 3535-3538. [CrossRef]

80. Pham, T.D.; Wardell, K.; Eklund, A.; Salerud, G. Classification of short time series in early Parkinsons disease with deep learning of fuzzy recurrence plots. IEEE/CAA J. Autom. Sin. 2019, 6, 1306-1317. [CrossRef]

81. Hoang, N.S.; Cai, Y.; Lee, C.-W.; Yang, Y.O.; Chui, C.-K.; Chua, M.C.H. Gait classification for Parkinson's Disease using Stacked 2D and 1D Convolutional Neural Network. In Proceedings of the 2019 International Conference on Advanced Technologies for Communications (ATC), Hanoi, Vietnam, 17-19 October 2019; IEEE: New York, NY, USA, 2019; pp. 44-49. [CrossRef]

82. Li, S.; Lei, H.; Zhou, F.; Gardezi, J.; Lei, B. Longitudinal and Multi-modal Data Learning for Parkinson's Disease Diagnosis via Stacked Sparse Auto-encoder. In Proceedings of the 2019 IEEE 16th International Symposium on Biomedical Imaging (ISBI 2019), Venice, Italy, 8-11 April 2019; IEEE: New York, NY, USA, 2019; pp. 384-387. [CrossRef]

83. Lee, S.; Hussein, R.; McKeown, M.J. A Deep Convolutional-Recurrent Neural Network Architecture for Parkinson's Disease EEG Classification. In Proceedings of the 2019 IEEE Global Conference on Signal and Information Processing (GlobalSIP), Ottawa, ON, Canada, 11-14 November 2019; IEEE: New York, NY, USA, 2019; pp. 1-4. [CrossRef]

84. Sayaydeh, O.; Mohammad, M.F. Diagnosis of the Parkinson Disease Using Enhanced Fuzzy Min-Max Neural Network and OneR Attribute Evaluation Method. In Proceedings of the 2019 International Conference on Advanced Science and Engineering (ICOASE), Zakho - Duhok, Iraq, 2-4 April 2019; IEEE: New York, NY, USA, 2019; pp. 64-69. [CrossRef]

85. Shi, X.; Wang, T.; Wang, L.; Liu, H.; Yan, N. Hybrid Convolutional Recurrent Neural Networks Outperform CNN and RNN in Task-state EEG Detection for Parkinson's Disease. In Proceedings of the 2019 Asia-Pacific Signal and Information Processing Association Annual Summit and Conference (APSIPA ASC), Lanzhou, China, 18-21 November 2019; IEEE: New York, NY, USA, 2019; pp. 939-944. [CrossRef]

86. Shah, P.M.; Zeb, A.; Shafi, U.; Alam Zaidi, S.F.; Shah, M.A. Detection of Parkinson Disease in Brain MRI using Convolutional Neural Network. In Proceedings of the 2018 24th International Conference on Automation and Computing (ICAC), Newcastle Upon Tyne, UK, 6-7 September 2018; IEEE: New York, NY, USA, 2018. [CrossRef]

87. Ajay, J.; Song, C.; Wang, A.; Langan, J.; Li, Z.; Xu, W. A pervasive and sensor-free Deep Learning system for Parkinsonian gait analysis. In Proceedings of the 2018 IEEE EMBS International Conference on Biomedical \& Health Informatics (BHI), Las Vegas, NV, USA, 4-7 March 2018; IEEE: New York, NY, USA, 2018; pp. 108-111. [CrossRef]

88. Adams, M.P.; Yang, B.; Rahmim, A.; Tang, J. Prediction of outcome in Parkinson's disease patients from DAT SPECT images using a convolutional neural network. In Proceedings of the 2018 IEEE Nuclear Science Symposium and Medical Imaging Conference Proceedings (NSS/MIC), Sydney, NSW, Australia, 10-17 November 2018; IEEE: New York, NY, USA, 2018; pp. 1-4. [CrossRef]

89. Xia, Y.; Zhang, J.; Ye, Q.; Cheng, N.; Lu, Y.; Zhang, D. Evaluation of deep convolutional neural networks for detection of freezing of gait in Parkinson's disease patients. Biomed. Signal Process. Control. 2018, 46, 221-230. [CrossRef]

90. Gong, B.; Shi, J.; Ying, S.; Dai, Y.; Zhang, Q.; Dong, Y.; An, H.; Zhang, Y. Neuroimaging-based diagnosis of Parkinson's disease with deep neural mapping large margin distribution machine. Neurocomputing 2018, 320, 141-149. [CrossRef]

91. Camps, J.; Samà, A.; Martín, M.; Rodríguez-Martín, D.; Pérez-López, C.; Arostegui, J.M.M.; Cabestany, J.; Català, A.; Alcaine, S.; Mestre, B.; et al. Deep learning for freezing of gait detection in Parkinson's disease patients in their homes using a waist-worn inertial measurement unit. Knowl. Based Syst. 2018, 139, 119-131. [CrossRef]

92. Prince, J.; De Vos, M. A Deep Learning Framework for the Remote Detection of Parkinson'S Disease Using Smart-Phone Sensor Data. In Proceedings of the 2018 40th Annual International Conference of the IEEE Engineering in Medicine and Biology Society (EMBC), Honolulu, HI, USA, 18-21 July 2018; IEEE: New York, NY, USA, 2018; Volume 2018, pp. 3144-3147. [CrossRef] 
93. Lahmiri, S.; Dawson, D.A.; Shmuel, A. Performance of machine learning methods in diagnosing Parkinson's disease based on dysphonia measures. Biomed. Eng. Lett. 2017, 8, 29-39. [CrossRef] [PubMed]

94. Martínez-Murcia, F.J.; Górriz, J.M.; Ramírez, J.; Ortiz, A. Convolutional Neural Networks for Neuroimaging in Parkinson's Disease: Is Preprocessing Needed? Int. J. Neural Syst. 2018, 28, 1850035. [CrossRef]

95. Zhang, X.; He, L.; Chen, K.; Luo, Y.; Zhou, J.; Wang, F. Multi-View Graph Convolutional Network and Its Applications on Neuroimage Analysis for Parkinson's Disease. AMIA Annu. Symp. Proc. 2018, 2018, 1147-1156. Available online: https: / / www.ncbi.nlm.nih.gov / pubmed/30815157 (accessed on 1 June 2021).

96. Loconsole, C.; Cascarano, G.D.; Lattarulo, A.; Brunetti, A.; Trotta, G.F.; Buongiorno, D.; Bortone, I.; De Feudis, I.; Losavio, G.; Bevilacqua, V.; et al. A comparison between ANN and SVM classifiers for Parkinson's disease by using a model-free computer-assisted handwriting analysis based on biometric signals. In Proceedings of the 2018 International Joint Conference on Neural Networks (IJCNN), Rio de Janeiro, Brazil, 8-13 July 2018; IEEE: New York, NY, USA, 2018; pp. 1-8. [CrossRef]

97. Pereira, C.R.; Pereira, D.R.; Rosa, G.H.; Albuquerque, V.H.; Weber, S.A.; Hook, C.; Papa, J.P. Handwritten dynamics assessment through convolutional neural networks: An application to Parkinson's disease identification. Artif. Intell. Med. 2018, 87, 67-77. [CrossRef] [PubMed]

98. Kim, H.B.; Lee, H.J.; Lee, W.W.; Kim, S.K.; Jeon, H.S.; Park, H.Y.; Shin, C.W.; Yi, W.J.; Jeon, B.; Park, K.S. Validation of Freezing-ofGait Monitoring Using Smartphone. Telemed. e-Health 2018, 24, 899-907. [CrossRef]

99. Vlachostergiou, A.; Tagaris, A.; Stafylopatis, A.; Kollias, S. Multi-Task Learning for Predicting Parkinson's Disease Based on Medical Imaging Information. In Proceedings of the 2018 25th IEEE International Conference on Image Processing (ICIP), Athens, Greece, 7-10 October 2018; IEEE: New York, NY, USA, 2018; pp. 2052-2056. [CrossRef]

100. Khojasteh, P.; Viswanathan, R.; Aliahmad, B.; Ragnav, S.; Zham, P.; Kumar, D.K. Parkinson's Disease Diagnosis Based on Multivariate Deep Features of Speech Signal. In Proceedings of the 2018 IEEE Life Sciences Conference (LSC), Montreal, QC, Canada, 28-30 October 2018; IEEE: New York, NY, USA, 2018; pp. 187-190. [CrossRef]

101. Khatamino, P.; Canturk, I.; Ozyilmaz, L. A Deep Learning-CNN Based System for Medical Diagnosis: An Application on Parkinson's Disease Handwriting Drawings. In Proceedings of the 2018 6th International Conference on Control Engineering \& Information Technology (CEIT), Istanbul, Turkey, 25-27 October 2018; IEEE: New York, NY, USA, 2018; pp. 1-6. [CrossRef]

102. Passos, L.A.; Pereira, C.R.; Rezende, E.R.S.; Carvalho, T.J.; Weber, S.A.T.; Hook, C.; Papa, J.P. Parkinson Disease Identification Using Residual Networks and Optimum-Path Forest. In Proceedings of the 2018 IEEE 12th International Symposium on Applied Computational Intelligence and Informatics (SACI), Timisoara, Romania, 17-19 May 2018; IEEE: New York, NY, USA, 2018; pp. 325-330. [CrossRef]

103. Vlachostergiou, A.; Tagaris, A.; Stafylopatis, A.; Kollias, S. Investigating the Best Performing Task Conditions of a MultiTasking Learning Model in Healthcare Using Convolutional Neural Networks: Evidence from a Parkinson's Disease Database. In Proceedings of the 2018 25th IEEE International Conference on Image Processing (ICIP), Athens, Greece, 7-10 October 2018; IEEE: New York, NY, USA, 2018; pp. 2047-2051. [CrossRef]

104. Zhang, H.; Wang, A.; Li, D.; Xu, W. DeepVoice: A voiceprint-based mobile health framework for Parkinson's disease identification. In Proceedings of the 2018 IEEE EMBS International Conference on Biomedical \& Health Informatics (BHI), Las Vegas, NV, USA, 4-7 March 2018; IEEE: New York, NY, USA, 2018; pp. 214-217. [CrossRef]

105. Marar, S.; Swain, D.; Hiwarkar, V.; Motwani, N.; Awari, A. Predicting the occurrence of Parkinson's Disease using various Classification Models. In Proceedings of the 2018 International Conference on Advanced Computation and Telecommunication (ICACAT), Bhopal, India, 28-29 December 2018; IEEE: New York, NY, USA, 2018; pp. 1-5. [CrossRef]

106. Moon, S.; Ahmadnezhad, P.; Song, H.-J.; Thompson, J.; Kipp, K.; Akinwuntan, A.E.; Devos, H. Artificial neural networks in neurorehabilitation: A scoping review. Neurorehabilitation 2020, 46, 259-269. [CrossRef] [PubMed]

107. Shahid, N.; Rappon, T.; Berta, W. Applications of artificial neural networks in health care organizational decision-making: A scoping review. PLoS ONE 2019, 14, e0212356. [CrossRef]

108. Shatte, A.B.R.; Hutchinson, D.M.; Teague, S.J. Machine learning in mental health: A scoping review of methods and applications. Psychol. Med. 2019, 49, 1426-1448. [CrossRef] [PubMed] 